\title{
A perspective on the health care expenditures for defensive medicine
}

\author{
Michael Osti ${ }^{1,2} \cdot$ Johannes Steyrer $^{3}$
}

Published online: 11 November 2016

(c) Springer-Verlag Berlin Heidelberg 2016

Predominantly concentrating on demography, income, and institutional and technological change, a wide array of determinants for health care expenditures has been studied to explain their rapid and alarming growth compared to the gross national product in all OECD countries. The predictors in Baumol's neoclassical model of unbalanced growth have been verified empirically and suggest an inevitable increase of prices in non-progressive sectors of economy with low productivity gains if demand for services is inelastic [2, 13, 37]. Consumer-driven health care inducing overtreatment, game theoretic approaches explaining irrational choices and imitative behavior among consumers and providers are well-established phenomena in the field of economics [17, 25, 40]. However, further aspects apparently seem to contribute to the expensive alteration of European health care services: defensive medical practice, i.e., a preventive medical approach characterized by both diagnostic exorbitance and therapeutic risk aversion, constitutes an adverse external effect of legal regulation and consumer choice, which can be analyzed and highlighted by explanatory models of social and behavioral economics [9, 18]. A considerable spectrum of information regarding the costs of defensive medicine for health care systems is

Michael Osti

michael.osti@lkhf.at

1 Department for Trauma Surgery and Sports Traumatology, Academic Hospital Feldkirch, Carinagasse 47, 6800 Feldkirch, Austria

2 Paracelsus Medical University Salzburg, Müllner Hauptstraße 48, 5020 Salzburg, Austria

3 Research Institute for Health Care Management and Health Care Economics, Vienna University of Economics and Business, Welthandelsplatz 1, 1020 Vienna, Austria reported in the literature $[21,22,24,33,42-44,47,48]$. Rubin and Mendelson [41] specified the defensive costs in the United States with US\$12 billion in 1987 and a duplication of these expenses until 1997. The potential cost savings over a period of 5 years were estimated with US\$41 billion by aggressive tort reform. Kessler and McClellan [22] identified annual expenditures for defensive medical practice between 5 and $9 \%$ of the entire health care budget in the United States. Derived from the average compensation from health insurance companies, Sethi et al. [44] estimate a national expenditure of US\$2 billion per year for orthopedic defensive practices in the US, exclusively. In addition to direct monetary expenses, also indirect costs as personal stress, loss of time and reputation for physicians, and a tendency to avoid the treatment of high-risk patients should be considered $[6,21]$. When affected by malpractice liability claims, physicians tend to aspire preterm retirement and advise their descendants against a career in the health care system [6]. Suspiciousness in personal insurance coverage and a financial burden by malpractice premiums are reported to be strong predictors for defensive practice [46]. A specification of costs must also include a potential gap in health care services, provoked by physicians' attitudes of avoiding high-risk patients, medicolegal prevention, and flight responses with changes of job and residence [36]. Studdert et al. [47] report that $93 \%$ of all medical high-risk specializations engage in defensive practices. A total amount of US\$4 billion was disbursed for 12,513 medical malpractice claims in the United States in 2006 [30]. Claims expenditures of German liability insurance companies have doubled to 120 million euros between 2000 and 2009. A positive correlation between increasing patient compensation and health care expenditures was demonstrated by Baicker et al. [1]. US federal states assigning high malpractice liability, registered increasing health care costs by 
$7 \%$ and a per-physician raise in expenditures of $4.2 \%$. Even though European literature recognizes the incorporation of defensive practice in routine medical services [50], a gap of knowledge about the factual costs of defensive medical practice is evident which contradicts the ethical and economic fact that decisions on the utilization of resources should be based on transparent criteria.

To assess expenditures and concomitants of defensive medical practice and to establish a solid basis for comprehension and discussion of potential adverse effects triggered by normative principles and behavioral patterns of economic agents on financing and controlling the Austrian health care system, 286 residents and consultants for orthopedic surgery, 1100 residents and consultants for trauma surgery, and 398 residents and consultants for radiology were invited to complete a study questionnaire and to reply to queries estimating the amount of diagnostic requests and defensive requests in a typical month, the monthly working time consumption for defensive practice and prior confrontations with malpractice liability claims. We found that annual labor costs for defensive practice amount to 42.4 million euros, allocated to orthopedic departments with 11.5 million euros, to trauma surgery departments with 23.5 million euros and to radiology departments with 7.4 million euros. Reduction or avoidance of defensive practice would liberate the financial resources for 425 full-time positions. Expenses for the medical services provided for defensive reasons amount to 420.8 million euros per year. Defensive imaging induces annual expenses of 270.4 million euros. In relation to ongoing public health care expenses for hospital-based intra- and extramural services of 13.2 billion euros in 2013 [4] and in relation to overall public health care expenses of 25.9 billion euros in 2012 [45], the shares of defensive diagnostic requests amount to 3.19 and to $1.62 \%$, respectively. A moderate correlation between patient contacts and defensive requests was found and male and experienced physicians tend to order less CT scans and short time observations but rely more frequently on routine blood samples and MRI, the latter also with increasing age. Statistically significant differences were found for the defensive request of short-term admissions and CT scans between male and female physicians. Defensive requests, defensive working time usage, and the count of malpractice liability encounters per month yielded a moderate-to-strong correlation. In contrast to a minor effort for defensive labor costs, the expenditures for defensive diagnostic services equal to a considerable monetary amount and are, although subject to methodical limitations, quite comparable to the results derived from US studies.

From the legal perspective, a mismatch between negligence and malpractice litigation is evident [51]. The core purposes of a liability system to focus on improvements in quality, safety, and appropriate compensation for affected patients is rarely met, which enhances tentativeness, legal uncertainty, and the risk of potential economic damage. Innovative legal considerations that alter the response of providers and liability insurers to medical injury and provide legal protection for adhering to evidence-based practice might create legal guaranty and trustability for physicians and inspire more cost-effective care [47]. Reimbursement mechanisms that induce financial responsibility for medical injuries for providers or offer pay-forperformance rewards for reducing injuries have also been suggested [14, 46, 47]. On the other hand, it seems still questionable whether offering compensation for all avoidable injuries, due to negligence or not, and providing early payments to eliminate litigation for negligence would be eligible measures to redress complications of medical treatment and provide incentives for safety improvement [47].

A malpractice liability system ideally provides compensation and corrective justice, producing additional psychological benefits for patients, and reduces future negligence by signaling legal sanctions to health care providers [31]. However, reliable evidence that quantifies these social benefits, the hypothesized deterrent effect of malpractice legislation, and, in particular, the extent of harmful externalities on physicians' reputational and emotional cost do not exist. The latter are reported to be presumably large, impair the quality of health care delivery, and intensify the adoption of a self-protective, riskaverse, and precautious behavior [31]. Furthermore, data acquisition on the amount of claims, lawsuits, or settlements against physicians as well as on patient compensations is deficient or lacking in several European countries.

The standardization of penalties for the neglect of duty within the partnership of medical treatment does not signal considerations and development of safety culture and management but increases documentation and induces defensive strategies without contributing to the reduction of medical error [24]. Supporting an intensification of liability, stimulating liability accusation, and simultaneously expecting physicians' collaboration in the clarification of medical error does not correlate to the cooperative conception of medical treatment [24]. Whereas recognition and learning from medical error is appreciated, standardization of liability might hardly yield any effect on the efficiency-raising modification of behavior [16]. Exacerbation of liability provokes increasing efforts and costs for avoidance by potential originators of loss [16]. Therefore, the preventive character of liability law is not completely acknowledged within jurisprudence. Not the fear of sanctions but the balanced conduct and the deduction of a conscious and deliberate decision in clinical organization, with the introduction of new treatment options and with 
respect to technical configurations [20] are the substantial requirements for the effective regulation by a legal norm [24]. Independent from either civil, criminal, or extrajudicial proceedings, from being defendant or uninvolved and from the final adjudication, physicians might rather tend to perceive any juridical appeal as personal accusation, any corresponding patient as opponent and would hardly recognize any acceptable or reasonable effect of such accusation on patient safety and autonomy or on improvement on treatment algorithms. Instead, daily clinical routine becomes increasingly contaminated by animosities and an unbalanced invective towards both legal representatives and patients.

On the other hand, several observations indicate a substantial mismatch between individual perception and actual facts. In Austria, 673 patients received extrajudicial compensation in 2012 and 5076 cases from public hospitals were processed by Austrian patient advocacies resulting in a compensation rate of $13.3 \%$. The annual average between 2003 and 2012 amounts to 609 patients per year. Within the past 5 years, the total amount of appeals to patient advocacies has fluctuated between approximately 9500 and 10,500 cases. Any precise assessment of the interrelation between medico-legal climate and defensive medical practice appears elusive, since comprehensive data summarizing compensation payments and annual development of cases is only available for patient advocacies but not for insurance companies and court mandates in Austria. Nevertheless, the results of previous investigations indicate that orthopedic and trauma surgeons perceive an average count of confrontations with malpractice liability claims of 1.2 cases per month and predominately estimate an increasing defensive trend within clinical routine during the past 5 years [34]. Extrapolating this value to the count of all employed registrars and residents in orthopedics and trauma surgery in Austria would result in a hardly conceivable 29,670 malpractice liability appeals to patient advocacies, insurance companies, and civil courts per year exclusively for these two specializations. Even though malpractice activity development seems to be rather stable and the patient compensation rate is still proportionally low when compared to the total annual count of treatments performed in Austrian hospitals, both medical and legal representatives identify a substantial demand for either defensive or aggressive strategies to control putative misconduct of the respective counterpart: availability and affect heuristics [49], illusory correlation [10], and correspondence bias [12] provide effectual explanations for the inconsistent observation that rational considerations are replaced by systematic misjudgment. In the present context, the protagonists of medical, legislative, and jurisdictive systems tend to rationalize deficient behavior ex post and establish their argument based on information that is accessible only in retrospect [11].

Hazardous incidents cause an intuitive tendency to identify individual causation and responsibility with penalizing solutions. Based on a linear correlation between malpractice and negligence of duties and obligations, this model underestimates organizational contexts [6]. Considering its voluntariness, action is subject to deliberate control and enables protagonists to decide between safe and precarious behavior. Misconduct is explained by negligence, carelessness, inaccuracy, or incompetence. Individual blame logic is unable to change a prevailing status or improve an organizational structure. This focus on the past compels participants to suspect legal debates and sanctions and negatively interferes with reporting systems for critical incidents and organizational learning.

Therefore, failures are concealed and defensive medical practices put into service [32]. To stimulate patient safety, health care organizations should abandon a retrospective focus on adverse side effects and aspire a proactive process of optimization that anticipates and deactivates vulnerabilities [3]. Resilient organizations [15] recognize potentially hazardous conditions, adapt accordingly, and absorb aberrations prior to risky consequences [36].

It is well established that medical standards rapidly adapt to abstract legal standards in the presence of nonsystem pressure, concealed behind the promised protection of consumer rights of information on the state of scientific knowledge and sustainable lessons learned from medical error by representatives not familiar with the medical profession and occupied merely with reprocessing an expost assessment of a diagnostic and therapeutic process. This illustrates the social trap of consumer behavior between counterfactual claims of contrarian and constricted rationalities. Induced by excessive corresponding supply on both sides, actors inquire medical and legal services because of post-contractual opportunism, moral hazard, copycatting, and information asymmetry. Conflicting revenge by denial, lack of comprehension, and reciprocity still seem to dominate the current controversy around the juridification of medical practice, deviate the relation of participants to exploitation and rivalry, select self-optimization and egocentricity, and might eventually diminish the social return on investment. Avarice, fear, and revenge as substantial boosters for conflict seem to be well represented in an analysis of this model and might induce considerable negative external effects on the national economy. The escalation process for risk-averse decisions in the presence of ambivalent alternatives with low probabilities for significant losses represented by the overweighting of potential harm among physicians and the over-estimation of potential benefit de jure as predicted by 
the prospect theory lead to overconfidence bias, status quo bias, and anchoring effects as well as reciprocal insult and mutual stigmatization among actors.

In this context, patient's legal representatives seem to add little to the improvement of patient safety and the prevention of medical risk. Compensation payments, regardless of negligence or fault, ignore the problem of approaching patients as customers, and communicate a mechanic and contractual rather than a human and collaborative pattern of interaction between physician and patient, simultaneously concentrating on institutional and public sector logics of commercialism and depersonalization instead on societal responsibilities. Diagnostic and therapeutic delays, if not negligent or careless, as well as inferior outcome or complicated therapeutic course, are also inherent to structural, organizational, and technical properties of health care systems as well as on the characteristics of disease and injury and particular medical conditions and are therefore neither susceptible by safety implementation and risk management nor allocatable in person by blaming participants of a corporate process. Scrutinizing these facts as potential damage and harm seems to be at least equivocal. Legislature, medical jurisdiction, and patient advocacies would be well advised to perceive their impact on and responsibility for evolving societal trends and damaging influence on therapeutic alliances, which try to enhance the physical status of humans who predominantly request medical, not legal, services. The professional liaison in medical treatment per se demands the mutual comprehension of all stakeholders involved. The lucrative effect of bilateral proposals of cooperative conduct, instead of preventive defection and opposition on performance and common welfare, must be realized and stimulated to achieve effectiveness and a reasonable allocation and distribution of resources.

Substantial evidence for the potential harmful effect of defensive medicine on patient safety and integrity has been provided by DeKay and Ash [7] discussing the threshold approach of clinical decision-making according to Pauker and Kassirer [38, 39]. A combination of riskbenefit-assessment of diagnostic tests with the probability of a disease based on the Bayes theorem for conditional probabilities resulted in the insight that variation in the a priori probability for test utility related to patient benefit versus disease detection significantly increases the risk for health damage since, besides of procedural risks, the probability for false-positive and false-negative results rises proportional to the quantity of tests performed [27, 28, 38, 39]. Potential harm of inappropriate test procedures depends on test risk, the share of false test results, the medical utility, and the risk of available treatment options and the a priori probability for the existence of the disease [35].
A significant mechanism of diagnostic certainty has been elucidated by Kassirer: "absolute certainty in diagnosis is unattainable, no matter how much information we gather, how many observations we make, or how many tests we perform" [19]. This reflects the tendency to control nature by a predominant subject, which attempts to identify, regulate, and confine possible hazards ex ante by implementing security policies. Confidence in technology and science leads to efforts of governing environment by rationality and transforms dangers into threats, for which probabilities can be rationally calculated, to which action can be referred and which are based on appropriate options for decision [26, 29]. Contingent future, perceived as risk per se and decoupled from fate and chance, becomes the central anchor of reference and therefore the basis of social uncertainty in modern societies [26].

The de facto demand for legal representation of patients that fall victim to medical malpractice, avoidable complications, or negligence remains unclear, appears to rise over time, and might presumably be induced by increasing supply following the economic principles of inefficient markets. Reasoning from a report about malpractice and preventable fatal causalities in US hospitals [23], Catino assigns a hardly realistic annual loss of US\$29 billion for the US national economy to medical errors that would rank at the 8th position for causes of deaths [5]. De Vries et al. [8] demonstrated that iatrogenic damage to hospital patients occurs in only $9.2 \%$, of which $43 \%$ would have been avoidable and $56 \%$ did not provoke any serious consequences.

The replacement of the notable efforts for self-protection by improvements in education in and maintenance of diligence, commitment, and empathy would doubtlessly better enhance patient safety and reliability than the comparative and deliberative behavior of defensiveness since encouraging the supremely human resources of communication and mutuality within the physician-patient-interaction might still be an eligible and fundamental objective for sophisticated societies.

Regulating as well as arguing for disproportionate consumer expectations means regulating against the voluntariness, commitment, and willingness of medical professionalism and would further compromise and restrict social coherence in a societal structure fraught with alarming competitive and adversarial behavior patterns. The necessity for clarification of deficient treatment remains beyond question.

Returning finally to Baumol's theory of unbalanced growth [2] that would rather suggest the stimulation of productivity growth within the healthcare system to manage cost accumulation, defensive medical practice, and especially the concepts of governmental as well as legal regulation that determine its origin and increase, definitely 
trigger the very contrary effect, i.e., the loss of productivity and receding resources in both capital endowment and work performance. With permanently rising expenditures for health care services, any additional congestion of the system with irrationality and arbitrariness seems to be utterly unaffordable and deleterious. Physicians might be compatible associates in the dialogue about the pervasive climate of destructiveness and despondence in the public sector of medical care and should be invited to participate in the proliferous reform of organizational, socio-economic, and legal preconditions for the health care system. Currently, however, specific governmental and legal regulations as well as organizational and individual behavior patterns seem to result in negative external effects, impairing both the optimal allocation of resources and interpersonal relations. This evidence should legitimate the urgent confrontation with increasing efforts of self-protection within the healthcare system.

\section{References}

1. Baicker, K., Fisher, E.S., Chandra, A.: Malpractice liability costs and the practice of medicine in the Medicare program. Health Aff. 26, 841-852 (2007)

2. Baumol, W.J.: Macroeconomics of unbalanced growth: the anatomy of urban crisis. Am. Econ. Rev. 57, 415-426 (1967)

3. Benn, J., Healey, A.N., Hollnagel, E.: Improving performance reliability in surgical systems. Cogn. Tech. Work 10, 323-333 (2008)

4. Bundesministerium für Gesundheit: Krankenanstalten in Zahlen. Überregionale Auswertung der Dokumentation der landesgesundheitsfondsfinanzierten Krankenanstalten. Bundesministerium für Gesundheit, Wien (2014)

5. Catino, M.: Why do doctors practice defensive medicine? The side-effects of medical litigation. Saf. Sci. Monit. 15, 1-12 (2011)

6. Charles, S.C., Wilbert, J.R., Franke, K.J.: Sued and non-sued physicians' self-reported reactions to malpractice litigation. Am. J. Psychiatry 172, 437-440 (1985)

7. DeKay, M.L., Asch, D.A.: Is the defensive use of diagnostic test good for patients, or bad? Med. Decis. Making 18, 19-28 (1998)

8. De Vries, E.N., Ramrattan, M.A., Smorenburg, S.M., Gouma, D.J., Boermeester, M.A.: The incidence and nature of in-hospital adverse events: a systematic review. Qual. Saf. Health Care 17, 216-223 (2008)

9. DiMaggio, P.J., Powell, W.W.: The iron cage revisited: institutional isomorphism and collective rationality in organizational fields. Am. Sociol. Rev. 48, 147-160 (1983)

10. Fiedler, K.: Illusory correlations: A simple associative algorithm provides a convergent account of seemingly divergent paradigms. Rev. Gen. Psychol. 4, 25-58 (2000)

11. Fischoff, B.: Hindsight is not equal to foresight: the effect of outcome knowledge on judgment under certainty. J. Exp. Psychol. Hum. Percept. Perform. 1, 288-299 (1975)

12. Fiske, S.T., Taylor, S.E.: Social cognition. Random House, New York (1984)

13. Hartwig, J.: What drives health care expenditure? Baumol's model of 'unbalanced growth' revisited. J. Health Econ. 27, 603-623 (2008)

14. Hermer, L.D., Brody, H.: Defensive medicine, cost containment, and reform. J. Gen. Intern. Med. 25, 470-473 (2010)
15. Hollnagel, E., Woods, D.D., Leveson, N.: Resilience engineering: concepts and precepts. Ashgate, Aldershot (2006)

16. Jansen, N.: Die Struktur des Haftungsrechts. Mohr Siebeck, Tübingen (2003)

17. Kahnemann, D.: A psychological perspective on economics. Am. Econ. Rev. 93, 162-168 (2003)

18. Kahneman, D., Tversky, A.: Prospect theory: an analysis of decision under risk. Econometrica 47, 263-291 (1979)

19. Kassirer, J.P.: Our stubborn quest for diagnostic certainty. A cause of excessive testing. N. Engl. J. Med. 320, 1489-1491 (1989)

20. Katzenmeier, C.: Arzthaftung, 1st edn. Mohr Siebeck, Tübingen (2002)

21. Kessler, D.P.: Evaluating the medical malpractice system and options for reform. J. Econ. Perspec. 25, 93-110 (2011)

22. Kessler, D.P., McClellan, M.: Do doctors practice defensive medicine? Q. J. Econ. 111, 353-390 (1996)

23. Kohn, L.T., Corrigan, J.M., Donaldson, M.S. (eds.): To err is human. Building a safer health system. National Academy Press, Washington, DC (2000)

24. Kubella, K.: Patientenrechtegesetz. Springer, Berlin, Heidelberg (2011)

25. Leung, M.V.M.: Primary care delivery, risk pooling and economic efficiency. Eur. J. Helath Econ. 11, 161-175 (2010)

26. Liessmann, K.P.: Die visionslose gesellschaft-mit unsicherheiten leben. Europäische Rundschau 31, 105-114 (2003)

27. Lippi, G., Plebani, M.: False myths and legends in laboratory diagnostics. Clin. Chem. Lab. Med. 51, 2087-2097 (2013)

28. Lippi, G., Cervellin, G., Plebani, M.: The ten commandments of laboratory testing for emergency physicians. Clin. Chem. Lab. Med. 52, 183-187 (2014)

29. Luhmann, N.: Soziologie des Risikos. De Gruyter, Berlin, New York (1991)

30. McGwin, G., Wilson, S.L., Bailes, J., Pritchett, P., Rue, L.W.: Malpractice risk: trauma care versus other surgical and medical specialties. J. Trauma 64, 607-613 (2008)

31. Mello, M.M., Chandra, A., Gawande, A.A., Studdert, D.M.: National costs of the medical liability system. Health Aff. 29, 1569-1577 (2010)

32. Merry, A., Smith, A.M.C.: Errors, medicine and the law. Cambridge University Press, Cambridge (2001)

33. Miller, R.A., Sampson, N.R., Flynn, J.M.: The prevalence of defensive orthopaedic imaging: a prospective practice audit in Pennsylvania. J. Bone Joint Surg. 94, 1-6 (2012)

34. Osti, M., Steyrer, J.: A national survey of defensive medicine among orthopaedic surgeons, trauma surgeons and radiologists in Austria: evaluation of prevalence and context. J. Eval. Clin. Pract. (2015). doi:10.1111/jep.12305

35. Owens, D.K.: Defensive diagnostic testing-a case of stolen utility? Med. Decis. Making 18, 33-34 (1998)

36. Patterson, E.S., Woods, D.D., Cook, R.I., Render, M.L.: Collaborative cross-checking to enhance resilience. Cogn. Tech. Work 9, 155-162 (2007)

37. Pammolli, F., Riccaboni, M., Magazzini, L.: The sustainability of European health care systems: beyond income and aging. Eur. J. Health Econ. 13, 623-635 (2012)

38. Pauker, S.G., Kassirer, J.P.: The threshold approach to clinical decision making. N. Engl. J. Med. 302, 1109-1117 (1980)

39. Pauker, S.G., Kassirer, J.P.: Decision analysis. N. Engl. J. Med. 316, 250-258 (1987)

40. Pombo-Romero, J., Varela, L.M., Ricoy, C.J.: Diffusion of innovations in social interaction systems. An agent-based model for the introduction of new drugs in markets. Eur. J. Health Econ. 14, 443-455 (2013)

41. Rubin, R.J., Mendelson, D.N.: Estimating the costs of defensive medicine. Lewin-VHI, Falls Church (1993) 
42. Ridic, G., Howard, T., Ridic, O.: Medical malpractice in Connecticut: defensive medicine, real problem or a red herring-example of assessment of quality outcomes variables. Acta Inform. Med. 20, 32-39 (2012)

43. Sathiyakumar, V., Jahangir, A.A., Mir, H.R., Obremskey, W.T., Lee, Y.M., Apfeld, J.C., Sethi, M.K.: The prevalence and costs of defensive medicine among orthopaedic trauma surgeons: a national survey study. J. Orthop. Trauma 27, 592-597 (2013)

44. Sethi, M.K., Obremskey, W.T., Natividad, H., Mir, H.R., Jahangir, A.A.: Incidence and costs of defensive medicine among orthopedic surgeons in the United States: a national survey study. Am. J. Orthop. 41, 69-73 (2012)

45. Austria, Statistik: Volkswirtschaftliche Gesamtrechnungen, eigene Berechnungen, Schätzungen, Rechnungsabschlüsse, Geschäftsberichte. Bundesanstalt Statistik Österreich, Wien (2014)

46. Studdert, D.M., Mello, M.M., Brennan, T.A.: Defensive medicine and tort reform: a wide view. J. Gen. Intern. Med. 25, 380-381 (2010)
47. Studdert, D.M., Mello, M.M., Sage, W.M., DesRoches, C.M., Peugh, J., Zapert, K., Brennan, T.A.: Defensive medicine among high-risk specialist physicians in a volatile malpractice environment. JAMA 293, 2609-2617 (2005)

48. Traina, F.: Medical malpractice. The experience in Italy. Clin. Orthop. Relat. Res. 467, 434-442 (2009)

49. Tversky, A., Kahneman, D.: Judgment under uncertainty: heuristics and biases. In: Bazerman, M.H. (ed.) Negotiation, decision making and conflict management, 1-3 edn, pp. 251-258. Edward Elgar, Northampton (2006)

50. Ulsenheimer, K.: Ausgreifende arzthaftpflichtjudikatur und defensivmedizin-ein verhältnis von ursache und wirkung. Humanitas, Dortmund (1997)

51. Waters, T.M., Studdert, D.M., Brennan, T.A., Thomas, E.J., Almagor, O., Mancewicz, M., Budetti, P.P.: Impact of the national practitioner data bank on resolution of malpractice claims. Inquiry 40, 283-294 (2003) 